IP Periodica Polytechnica Electrical Engineering and Computer Science

60(4), pp. 223-231, 2016

DOI: $10.3311 /$ PPee.9690

Creative Commons Attribution (i)

RESEARCH ARTICLE

\section{Advances in Producing Functional Circuits on Biodegradable PCBs}

\author{
Bálint Kovács ${ }^{1}$, Attila Géczy ${ }^{1 *}$, Gergely Horváth ${ }^{1}$, István Hajdu ${ }^{1}$, \\ László Gál ${ }^{1}$
}

Received 01 July 2016; accepted 27 July 2016

\begin{abstract}
In this paper a summary of our novel research results are presented about advances in producing functional electronic devices on environmentally friendly Printed Circuit Boards. The process of production and selected examples are shown for functional electronics (different RFID cards, with Mifare $1 K I C$ and a functional MP3 player). Avoiding traditional epoxy-based FR4 substrates in production may help in the reduction of harmful e-waste materials. The prototyping and production steps are focused on traditional PCB technologies to obtain cost-effective processes. Manufacturing steps are described; the obtained technology investigation results and functional results of FR4, cellulose-acetate (CA) and novel bioepoxy based circuits are presented. Evaluation tests show proper functionality on the environmental friendly substrates. Further weaknesses are highlighted for future improvements of reliability and durability for actual commercial use.
\end{abstract}

\section{Keywords}

biodegradable, PCB, cellulose-acetate, polylactic acid, RFID

\footnotetext{
${ }^{1}$ Department of Electronics Technology

Faculty of Electrical Engineering

Budapest University of Techology and Economics

H-1111 Budapest, Egry J. u. 18., Hungary

*Corresponding author, e-mail: gattila@ett.bme.hu
}

\section{Introduction}

Electronics production is increasing every year; due to the amount of the manufactured devices, the situation of harmful electronic waste is also escalating [1]. The industries must find innovations and new solutions to reduce the harmful materials found in electronic waste. The problem is also increased with the global market-based mindset, where the consumer is encouraged to dispose the obsolete, outdated hardware pieces and devices.

Some regulations were initated recently holding back hazardous materials from electronics manufacturing (as an example: RoHS [2-3]). Proper recycling is also an important question, while the majority of electronic devices and modules are essentially non-degradable.

\section{Biodegradables and environmental friendly materials in electronics}

Bioplastics are special polymers, which become well known in the 1950's, with the invention of amylomaize. Bioplastics $[4,5]$ can be compostable and biologically degradable, (according to DIN 12432 standard [6]) or plastics based on renewable resources. Bioplastics have several sub-classes [4] such as:

- Biodegradable or compostable but not bio-based

- Biodegradable or compostable and bio-based

- Non-biodegradable but bio-based

Printed Circuit Boards (PCBs) are critical parts of an electronic assembly from the aspect of waste processing. Only a few examples are listed in the literature about the applicability of environmental-friendly substances for electronic use, and despite the advantageous properties of the materials, they are rarely introduced for consumer electronics.

Using biodegradables as PCBs do not mean that these materials will degrade during their life cycle. The point is, that when the device ends its life time, turns into e-waste, the processing becomes easier and more eco-friendly. The disadvantages include reduced thermal stability and reduced mechanical performance, however constant improvements are presented in the available studies from different aspects. Staat et al. investigated 
electric and mechanical performance of biodegradable substrates with different additives improving on the basic substrates [7-9]. It was also shown that thermal stresses must be optimized for the curing of screen printed conductive pastes onto biodegradables. Ohki et al. $[10,11]$ investigated electric breakdown on biodegradables. Mattana et al. investigated the applicability of Polylactic Acid (PLA) [12] for organic electronic assemblies. Quintero and Mattana [13] investigated PLA for sensorics applications. PLA was considered as a promising substrate for producing antennas at $2.45 \mathrm{GHz}$ [14]. Hwang et al. used PLA [15] for CMOS electronics. The team considered different biodegradables for use in the field of high performance microelectronics. These novel materials were poly caprol actone (PCL), poly glycolic acid (PGA) and polylactic co-glycolic acid (PLGA). They even added rice paper into their investigations. Cellulose acetate (CA) material was lately investigated as a possible substrate for RFID cards [16]. Schramm et al. [17] investigated the manufacturing possibilities of the degradable materials. Baecker [18] researched the degrading processes lately. Irimia-Vladu reviewed possibilities of using different biodegradable and biocompatibles [19]. Medgyes et al. [20] researched the electrochemical migration on biodegradable printed circuit boards.

Reinforced bioepoxies (not necessary biodegradables) may also be a possible future of PCB technology. Niedermann et al researched [21] glucose-based, carbon-fiber reinforced composites with improved $\mathrm{T}_{\mathrm{g}}$ (glass transition temperature, ${ }^{\circ} \mathrm{C}$ ) parameter, having similar performance a FR4 (Flame-Retardant Class-4) type PCBs. Modeling approaches are also involved to reveal theoretical performance of such materials. [22] Searching through the literature of the topic, the most recent publications are revolving around sensorics (K. Pal et al. [23], Kanaparthi and Badhulika [24] Luvisi et al. [25]). Rossiter et al. recently claimed, the field of robotics will also implement and use biodegradables [26]. Deng et al. investigated the life cycle assessment of flax-fibre reinforced epoxidized linseed oil composites [27] for electronics application. They also concluded that environmental impact caused at End-of-Life stage of boards is generally negligible compared to the production stage for both types (biobased, non biobased) of printed circuit board substrates. However, the biobased substrate significantly lowers fuel use for incineration during combustion scenario of waste processing. Staat also presented a study [28] about SMD assembling on biodegradables, where solder joints were evaluated with shear testing.

Our recent research was focusing on implementing the biodegradable materials for standard PCB production steps. We have compared PLA, CA and FR4 substrates [29] for the role of carrier substrate in printed wiring technology (with subtractive PCB production methodology).

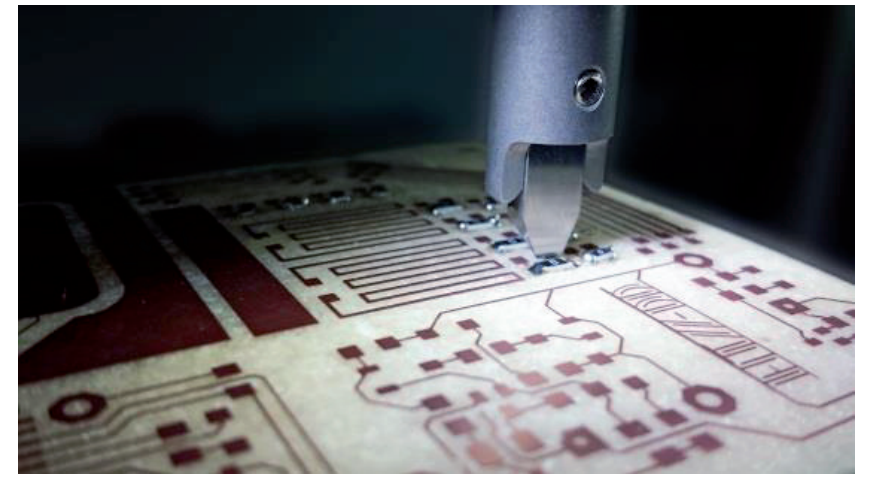

Fig. 1 Staat et al. investigated shear strenght of SMD components mounted on a PLA test circuit [28]

Investigations also focused on surface mount assembling of such boards [30] with different lead-free soldering alloys and vapour phase soldering (lately favoured by many research groups [31-33] for the case of reflow soldering). It was also highlighted recently, that vapour phase soldering may be extended for different new substrates in PCB technology [34].

We pointed to some limitations in our previous works regarding biodegradables: lower glass transition temperature and lower melting point can be a problem during melting of the solder. With low melting temperature Tin-Bismuth type solders, promising results were achieved. Continuing the research, the focus turned to produce functional electronic devices demonstrating application possibilities of biodegradables in the field of consumer electronics.

\section{Materials and methodology \\ 3.1 Base materials as PCB substrates}

In our initial research it was found, that PLA boards (from commercialized Bi-3515 substrate) are too sensitive for heating during assembling (even for reflow soldering on low temperatures). For further experiments two different bio-based materials were chosen for extended investigations. Our previous experience showed that the use of CA can yield efficient board production so the main focus was on this type. A novel polymer was added to the investigations only in the recent period of the research. The material is a sugar-based epoxy resin (glucopyranoside - GPTE) with high glass transition temperature $\left(\mathrm{T}_{\mathrm{g}}\right)$, and diethylene-toluene-tetramine (DETDA) polymerizing material [35]. The material is bio-based (renewable), it is more eco-friendly then the usual epoxy in FR4, but not essentially biodegradable. The material was chosen as an alternative substitute to heat sensitive biodegradables.

$\mathrm{CA}$ requires special heating due to the lower $\mathrm{T}_{\mathrm{g}}$ values; low melting point, lead-free eutectic $58 \mathrm{Bi} / 42 \mathrm{Sn}$ pastes with the melting point of $138{ }^{\circ} \mathrm{C}$ can be used for reflow soldering on CA boards. GPTE has better $\mathrm{T}_{\mathrm{g}}$ than usual epoxy, which enables standard lead free soldering at $\sim 230^{\circ} \mathrm{C}$. The soldering methods may be controlled IR heating, controlled hot gas (convection) or vapour phase soldering (VPS), with carefully selected heat 
transfer values. Table 1 presents the glass transition temperature values of the used materials. It also shows $T_{g}$ of the previously used PLA material as a comparison, highlighting its low $\mathrm{T}_{\mathrm{g}}$.

Table 1 Glass transition temperatures $\left(\mathrm{T}_{\mathrm{g}}\right)$ of used materials

\begin{tabular}{ll}
\hline Materials & Glass transition temperatures $\left(\mathrm{T}_{\mathrm{g}}\right)$ \\
\hline$F R 4^{*}$ & $\sim 140-150^{\circ} \mathrm{C}$ \\
$\mathrm{CA}$ & $\sim 104^{\circ} \mathrm{C}$ \\
PLA & $\sim 82{ }^{\circ} \mathrm{C}$ \\
GPTE bioepoxy & $\sim 210^{\circ} \mathrm{C}$ \\
\hline
\end{tabular}

"Standard FR4 PCB

\subsection{PCB manufacturing of bio-based, environmentally friendly boards}

In our work, circuit preparation stared from the substrate board (PCB) manufacturing step. The CA and GPTE boards are prepared in similar manner. The polymer materials are molded with a Fontune SR100 machine at given elevated temperature setting and optimized pressure force. Copper foils are added to the top and the bottom sides of the boards during molding, forming a package for the following two sided subtractive PCB technology.

The actual PCB design is prepared in a circuit design tool (Mentor Graphics PADS in this case), where the design procedure is performed according to common design methodologies for two sided conventional PCBs with surface mounted components. Vias are also involved in the design.

Vias are prepared on the package with $\mathrm{CNC}$ technology, then wet polishing and drying follows in the procedure. The processed manufacturing files are used to prepare photolithography masks. Electroplating an initial conducting layer is also an important step into the trough holes. After another wet polishing and drying step, lamination of the photoresist mask follows, where the process temperature is at $135^{\circ} \mathrm{C}$. The temperature of the CA board exceeds its $\mathrm{T}_{\mathrm{g}}$, so this step must be performed at a maximum of the given temperature in order to avoid significant deformations. The development of the photoresist gives the desired mask pattern on the surface. An additional $25 \mu \mathrm{m}$ copper layer is added for the trough hole vias. Subtractive steps are used to finish the circuitry - where tin electroplating follows (on the traces) ultimately serving as a mask for the etching procedure. (Fig. 2 shows the boards after the step of etching.)

Solder mask application is not optimized for the CA boards yet (which omission is common at this step of basic research $[20,28])$, this part of the production needs optimizing to avoid deformation during the curing of the mask layer. However, solder mask can applied on GPTE substrates.

The final shape of the boards are cut out with CNC routing.

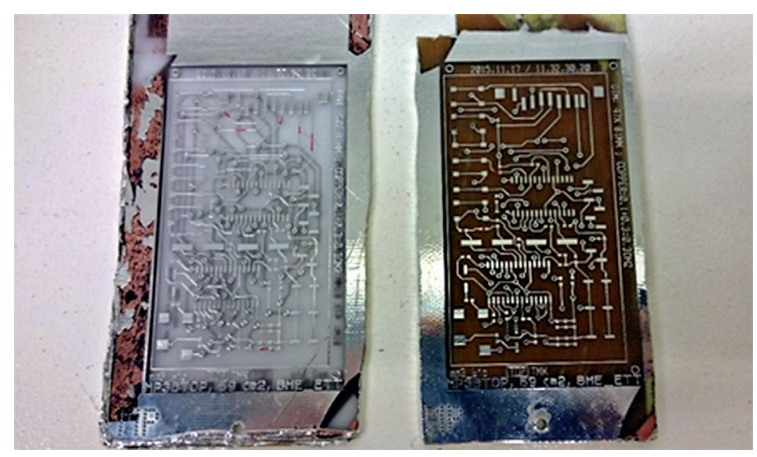

Fig. 2 CA (left) and GPTE (right) boards after etching step

\subsection{Test circuits}

As a demonstration of our tests with the environmental friendly substrates two different applications with three designs were aimed to be realized. The first demonstration was a simple circuit design for RFID tag applications based on a dedicated RFID integrated device, in order to demonstrate a straightforward working mechanism. The widely used $13.56 \mathrm{MHz}$ frequency was chosen with Mifare1K chips for all circuits, serving as a widely used commercial solution.

The first RFID card dimensions (Design_A) were based on the ISO 14443 standard $(85,6 \times 53,98 \times 0,76 \mathrm{~mm})$ [36]. At this stage of the research, the thickness was doubled, in order to match the standard PCB thickness values $(\sim 1.55 \mathrm{~mm})$, enabling more efficient production. In the case of contactless smart cards four main methods are used for coil manufacturing, according to Finkenzeller [37]. Winding, embedding, screen printing and etching, which last method is mainly associated with standard subtractive PCB production methodology. Due to the aim of our research, we chose this method for producing RFID tags. The actual coil dimension sizing was performed according to the X-Ray analysis of a commercial TWC-401-100 Mifare S50 card. (Fig. 2)

The reference TWC-401-100 Mifare S50 card was used later for evaluation as well. No measurement possibility was available for the inductivity of the coil, while any opening attempt resulted in damage of the material. So calculations were performed based on the geometry data investigated during microscopy analysis.

The calculations of the design followed the Grover model [38]:

$$
\begin{aligned}
& L_{R E C T} \approx N^{2} \cdot \frac{\mu_{0} * \mu_{r}}{\pi} \\
& {\left[\begin{array}{l}
-2(W+H)+2 \sqrt{H^{2}+W^{2}}-H \\
\cdot \ln \left(\frac{H+\sqrt{H^{2}+W^{2}}}{W}\right)-W \cdot \ln \left(\frac{W+\sqrt{H^{2}+W^{2}}}{H}\right)+H \\
\cdot \ln \left(\frac{2 \cdot H}{a}\right)+W \cdot \ln \left(\frac{2 \cdot W}{a}\right)
\end{array}\right],}
\end{aligned}
$$


where $\mathrm{N}$ is the number of turns, $\mathrm{w}$ is the width of the rectangle $[\mathrm{m}], \mathrm{h}$ is the height of the rectangle [m], a is the wire radius [m], $\mu_{0}$ is the permeability of free space, $\mu_{\mathrm{r}}$ is the relative permeability of the medium, $\mathrm{L}_{\mathrm{RECT}}$ is the desired inductance $[\mathrm{H}]$. The actual design followed the surface available on the actual card (Fig. 2), and was finalized in Mentor Graphics PADS. Figure 3 shows the progress from PCB design a.) to FR4 test board b.) and CA board c.) (segmented picture). Due to the fact, that FR4 test boards and CA boards performed similarly (later discussed in the results chapter), FR4 references were omitted from the other tag design.

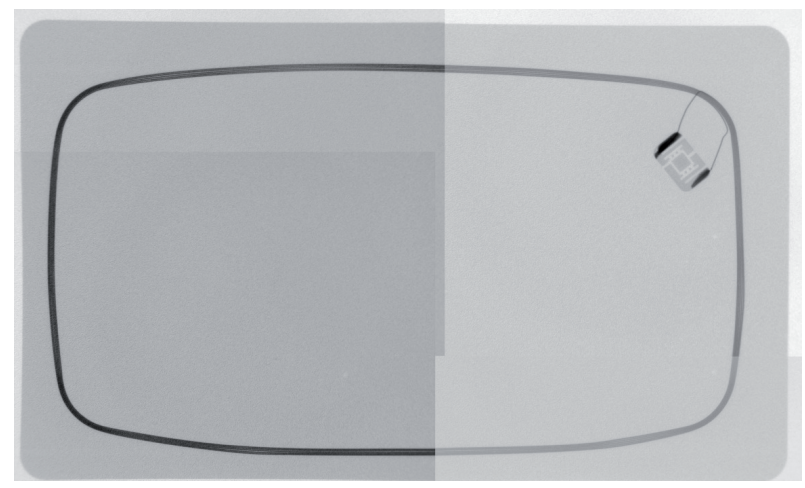

Fig. 3 Standard RFID coil and Mifare1K IC inside a ISO 14443 card observed through a segmented X-ray microscopy picture

According to Table 2 (approximated values from the PCB design and the manufacturing) the final inductance is around $\mathrm{L}_{\mathrm{RECT}} \approx 5,7 \mu \mathrm{H}$.

Table 2 Parameters of coil (dimension ranges according to the common PCB dimensions)

\begin{tabular}{ll}
\hline Parameters & Values \\
\hline $\mathrm{N}$ & 5 \\
$\mathrm{~W}[\mathrm{~mm}]$ & 79 \\
$\mathrm{H}[\mathrm{mm}]$ & 47.4 \\
$\mathrm{a}[\mu \mathrm{m}]$ & 0.3 \\
\hline
\end{tabular}

Then two smaller RFID tags were designed (Design_B_ Square and Design_B_Octagonal) according to a commercial Mifare1K keychain tag, with a standard coil antenna [39]. The antenna and its dimensions are shown in Fig. 2, which parameters were used in calculations of the inductivity.

The calculations (2) were performed according to Mohan [40]:

$$
L_{\text {SPIRAL }} \approx \frac{\mu_{0} \cdot N^{2} \cdot d_{\text {avg }} \cdot c_{1}}{\pi} \cdot \ln \left(\frac{c_{2}}{\rho}\right)+c_{3} \cdot \rho+c_{4} \cdot \rho^{2},
$$

where, $\mathrm{c}$ values are layout dependent constants [38] $\left(\mathrm{c}_{1}=1, \mathrm{c}_{2}=\right.$ $\left.2.46, \mathrm{c}_{3}=0, \mathrm{c}_{4}=0.2\right)$ and $\mathrm{d}_{a v g}$ can be calculated according to (3):

$$
d_{\text {avg }}=\frac{d_{\text {in }}+d_{\text {out }}}{2}
$$

where $d_{i n}$ is the inner diameter, $d_{\text {out }}$ is the outer diameter. $\rho$ is the fill ratio (4):

$$
\rho=\frac{\left(d_{\text {out }}-d_{\text {in }}\right)}{\left(d_{\text {out }}+d_{\text {in }}\right)} .
$$

According to (2), (3) and (4) the $\mathrm{L}_{\text {SPIRAL }}=7 \mu \mathrm{H}$, which is close in range to the previously discussed rectangular spiral. The inductance was measured also with a Hewlett-Packard 4275A LCR meter, where the value was $\mathrm{L}_{\text {SPIRAL MEAS }}=7,3 \mu \mathrm{H}$, showing, that the measured inductance value of the coil and the modelling calculation has $\sim 4.3 \%$ error, which is still acceptable in this case.

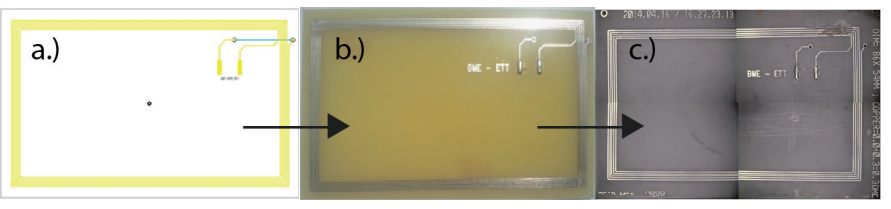

Fig. 4 RFID design for ISO 14443 standard card (a.) PCB design, b.) FR4 board, c.) CA board)

At this point, the task was to reproduce the inductance of the coil for similar dimensions which can be a fit for a keychain (there was no standardized sizing involved at this step). For layout design the aim was to use common PCB trace patterns which suit the most basic standard designs; so rectangular and octagonal shapes were chosen for final production. with $135^{\circ}$ trace angles. Table 3 shows the layout dependent constants used for the calculations.

Table 3 Layout dependent constants according to Mohan [40]

\begin{tabular}{lllll}
\hline Shape & $\mathrm{c}_{1}$ & $\mathrm{c}_{2}$ & $\mathrm{c}_{3}$ & $\mathrm{c}_{4}$ \\
\hline Square & 1.27 & 2.07 & 0.18 & 0.13 \\
Octagonal & 1.07 & 2.29 & 0 & 0.19 \\
\hline
\end{tabular}

Table 4 shows the final calculated parameters, characterizing the new coils, where the dimensions were optimized according to the following requirements:

- the design should follow the recommended design rules and limitations (such as trace width, clearance, dimensions) of the available PCB fabrication capabilities,

- the design should match the inductance of the reference coil (as shown below Fig. 4),

- the design should stay in a small overall size to match the dimensions of a keyring tag. 
Table 4 Calculated coil parameters

\begin{tabular}{lllll}
\hline Shape & dout & din & $n$ & $\mathrm{~L}_{\text {CALC }}$ \\
\hline Square & $40 \mathrm{~mm}$ & $25 \mathrm{~mm}$ & 11 & $7.1 \mu \mathrm{H}$ \\
Octagonal & $41 \mathrm{~mm}$ & $25 \mathrm{~mm}$ & 12 & $7.2 \mu \mathrm{H}$ \\
\hline
\end{tabular}

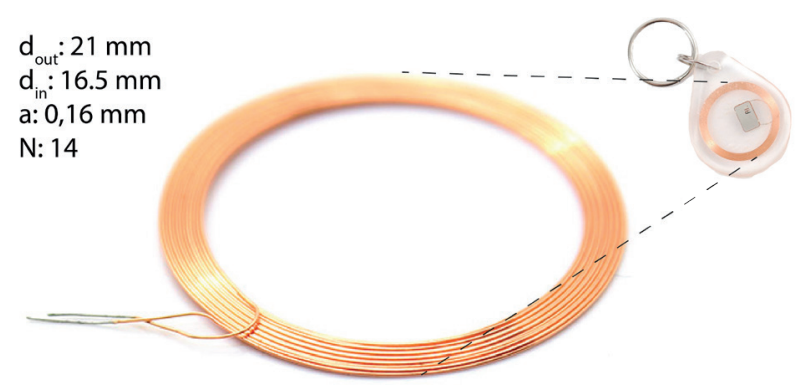

Fig. 5 Common RFID coil from keyring tag and dimensions

A design of an MP3 player (Design_C) was introduced later in our research, in order to step up from the simple RFID tag designs, to a more complex circuit setup. An MP3 player is complex enough to present varied selection surface mounted components on the board, and to show sophisticated wiring with trough hole vias on the PCB, which was a challenge first on the eco-friendly substrates. An open source MP3 Player [41] was chosen as a basis, with a PIC18LF2550 microcontroller, combined with a VS1011e decoder IC. The surface mounted components were selected according to the variety of required parts in the schematic, bearing in mind, that the demonstration should present small scale (down to 0603) discrete components, SM connectors (e.g. jack output and SD card slot), and SO packages for the integrated circuits.

The first FR4 board layout was designed according to a $4.5 \times 7 \mathrm{~cm}$ board outline, trace width was defined as $11 \mathrm{mil}$. The design aimed for two layers, one layer for SM components (TOP), and a bottom layer for wiring (BOT). The design has relatively high count of through hole vias (86) which may be interesting for the novel environmentally friendly substrates during evaluation.

Both approaches (RFID - Designs_A and B; MP3 Design C) were chosen to emphasize commonly understandable use of the technology.

\subsection{Assembly}

Assembling was performed with standard surface mounting, ensuring compatibility with currently adopted manufacturing technologies. Bi/Sn paste with $138^{\circ} \mathrm{C}$ melting point was used for CA (NC-SMQ81; 58Bi/42Sn) and SAC305 paste with $217{ }^{\circ} \mathrm{C}$ melting point was used for FR4 and GPTE boards. The solder paste was deposited with manual dispensing, then the components were mounted with a manual pick \& place machine. Soldering was performed with a hot gas blower for manual reflow soldering on CA, and an Euro Circuits eC Reflow Mate IR oven was used for FR4 and GPTE boards. Vapour phase soldering is an option for CA-based assembly production [20] (with the use of $170^{\circ} \mathrm{C}$ boiling point Galden fluid). Our VPS solution uses LabVIEW SW+HW setup to control the sample holder inside the oven for precise heat transfer. However for pilot tests, manual hot gas method was found to be more efficient and economical.

\subsection{Evaluation methods}

The measurement of the inductances were performed with the aforementioned Hewlett-Packard 4275A LCR meter.

For evaluation of the commercial and the proposed biodegradable based RFID cards, a SLO40 USB 13.56 MHz card reader was chosen to enable functional testing. The tests involved the reading distance evaluation of the RFID tags, where the exact distances were obtained with a Balluff BTL5 micropulse transducer. In this case, the card was fixed to a sample holder, then the reader was moved perpendicularly to the surface of the card with the measurement resolution of $0.01 \mathrm{~mm}$. The center of the coil was aligned to the center of the reader, which indicates the reading with a beep, and a signal to its USB software. Each tag was measured five times.

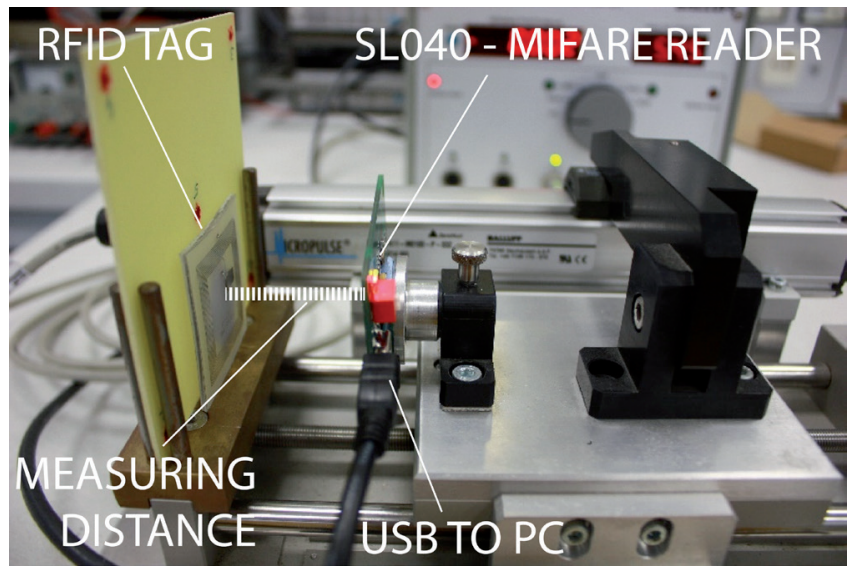

Fig. 6 Transducer setup used for distance measurements

From the aspect of assembling X-Ray inspection (Dage XD6600) was used to investigate any possible trace deformations, via problems, and solder joint shapes.

For functional testing of the MP3 players, music was played on commercial speakers and headsets. For a more thorough analysis, noise investigation was also initiated, where a silent MP3 file (practically an empty waveform, stored in $320 \mathrm{kbps}$ file) was played back. The player was connected via a stereo jack-jack cable to the "line in" input of an external audio card, set to $192.000 \mathrm{~Hz}$ sampling and 32-bit recording resolution. The MP3 file were played back from three assembled MP3 player devices (FR4, CA, bioepoxy). The voltage source was a battery pack to avoid any noise coupled from a laboratory power source. A digital audio workstation was used to record the wave files. The recorded, high resolution wave file was processed with Matlab to calculate the output spectrum. The complete setup is presented on Fig. 7. 


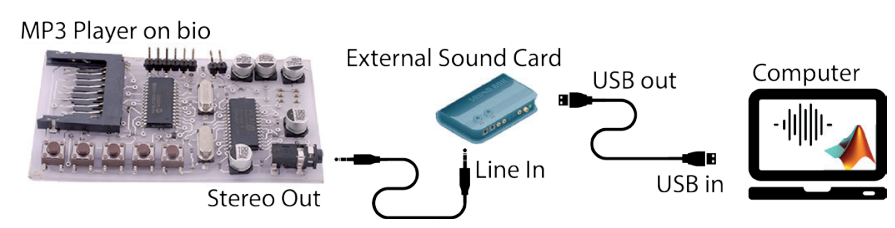

Fig. 7 Transducer setup used for distance measurements

\section{Results}

In the chapter, the given results are separated according to the technological results, and the functional aspects.

\subsection{PCBs and assemblies}

The PCB production was successful for every board, but only after continuous optimizations of the process. The following problems occurred, which required further care and attention during production. Initially the trace adhesion was very weak in quality aspects. In order to prevent use of any additional pre-preg epoxy layers, the initial step of moulding and lamination was optimized, to achieve sufficient (as discussed in [42]) copper adhesion. The surface of the copper foil, the moulding heads have to be cleaned and aligned properly in order to obtain proper copper adhesion. If this step fails, then problems will occur in the further steps of the production.

During assembly, the most critical part of the process is heat transfer, where over exceeding heat may cause serious delamination on the sensitive CA. This was already optimized in our previous works [30].

During the manufacturing, GPTE bioepoxy substrate suffered minor cracking due to its stiffness. It was concluded that further optimization (reinforcement) is needed for GPTE PCB production. At this stage this result was accepted, as the investigations with GPTE were only performed as a pilot experiment.

Further research is required to improve the mechanical stability of CA (as discussed in [30]), however at this point any reinforcement application was still out of our focus. Figure 8 shows the assembled circuits.

A.)

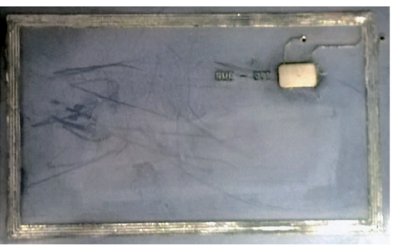

B.)
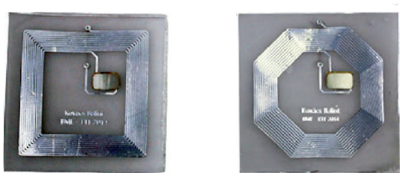

Fig. 8 Assembled circuits. A.) pilot RFID card based on ISO 14443; B.) square (left) and octagonal (right) tags; C.) MP3 players from FR4 (top), CA (middle) and GPTE (bottom).
$\mathrm{X}$-Ray analysis is able to reveal trace deformations or improper soldering of the Mifare1K IC on Design_A and B. With X-Ray analysis we were able to locate shorts and delaminations between the turns of the coils. The X-Ray analysis helped in the iteration and optimization of the PCB manufacturing. Figure 9 shows an example of trace analysis with the X-Ray microscope.

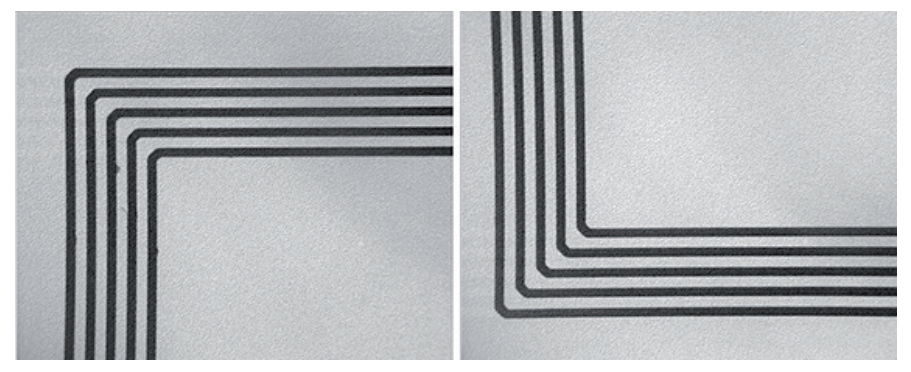

Fig. 9 Trace analisis on Design_A CA RFID card.

$\mathrm{X}$-Ray analysis is more relevant in the case of the MP3 player (Design C). The boards were investigated from the aspect of via quality, traces, deformations and the overall quality of solder joints. With our previous experience ([30]), major problems of deformations could be avoided, also no critical problems were observable in either of the cases. Solder joint shapes and void content on bio-based boards conformed with the FR4 boards. One minor issue still needs further improvements SM connectors showed minor angular offsets due to manual assembling.
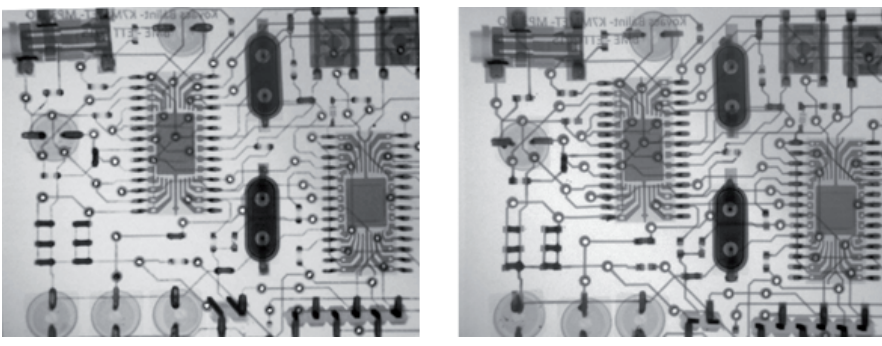

Fig. 10 X-Ray inspection of Bioepoxy (L) and CA (R) assemblies from the aspect of via quality, traces and solder joings.

\subsection{Functional aspects of RFID cards (Designs_A,B)}

From functional aspects the RFID tags were investigated according to their calculated and measured inductances. According to Table 5, the rectangular coil in the ISO 14443 card has the largest error compared to the theoretical values, which may be due to the imprecision of the applied model for calculations, and imprecision coming from the PCB manufacturing. From practical aspects however, as Fig. 8 shows, the distance measurements were really similar for the reference ISO 14443 card and the FR4 and CA reproductions. Due to the functional similarity between FR4 and CA, FR4 was omitted from further RFID investigations. The distance measurement deviations (Fig. 11) were minimal; any slight deviation may be due to practical imprecisions of the transducer setup presented on Fig. 6. 
Table 5 Calculated and measured inductance values

\begin{tabular}{llll}
\hline RFID tag & $\mathrm{L}_{\text {CALC }}$ & $\mathrm{L}_{\text {MEAS }}$ & Error \\
\hline Design_A & $5,7 \mu \mathrm{H}$ & $4,9 \mu \mathrm{H}$ & $-14 \%$ \\
Design_B_Square & $7,1 \mu \mathrm{H}$ & $6,8 \mu \mathrm{H}$ & $-4.2 \%$ \\
Design_B_Octagonal & $7,2 \mu \mathrm{H}$ & $7,1 \mu \mathrm{H}$ & $-1.4 \%$ \\
\hline
\end{tabular}

From the aspect of Design_B (the keyring design), the original RFID keyring tag was readable from a slightly smaller distance. This is due to the extended planarity of the Square and Octagonal coils originated from the PCB design, compared to the original coil (Fig. 5) found in the keyring tag. The scale of the deviances are again negligible.

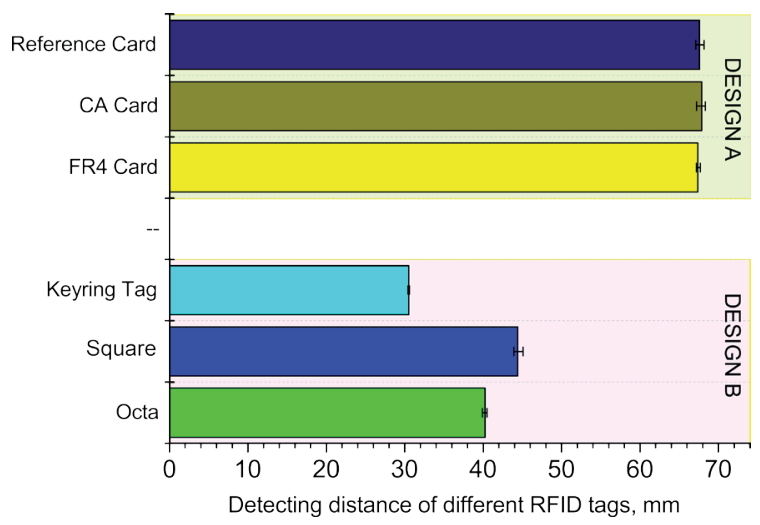

Fig. 11 Functional tests - reading distances

Summing up, the functional aspects of the produced tags were sufficient from the practical point of view.

\subsection{Functional aspects of MP3 player (Design_C)}

The functional tests resulted in promising results, where the played music file was clearly hearable with unrecognizable differences between the different devices. Matlab analysis of the recorded 2 second silent sound files gave practically similar output spectra for every produced and investigated board. Figure 12 shows the spectra recorded from three different boards, where the frequency is shown at an extended audible region.

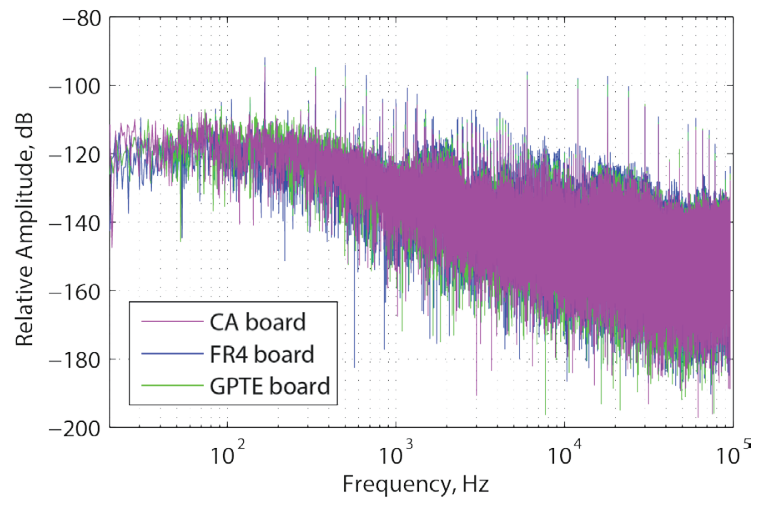

Fig. 12 Output spectra of "silent" MP3 file on three different boards
The relative amplitude is staying at generally low levels with similar plots. At the investigated frequency range (extended audible frequencies), all MP3 players on the given boards are performing similarly. So from the aspect of practical utility, no differences can be distinguished between the classical FR4 board or the environmentally friendly boards.

\section{Conclusion}

In this paper a summarized report is presented about our progress in producing functional, commercial electronics on biodegradable Printed Circuit Boards (PCB). The results showed promising examples of working circuits with adequate functionality. Practically the presented circuits showed matching performances with the references from this aspect.

It was found, that the moulding and copper laminating process is very sensitive from the aspect of copper adhesion on the substrate. The heat transfer processes also require increased attention, due to the low glass transition temperature of the CA material. Also during our extended operation tests by users, more serious mechanical stresses (such as bending in a pocket) may induce damage of the traces on the boards, which may point to the eventual use of reinforcement materials, or from an other point of view: proper casing. GPTE boards may suffer minor cracking during soldering, or heavier mechanical load, so additional investigations are needed for the bio-based substrate, to characterize and improve this aspect of the carriers.

Future improvements should be focusing on the mechanical tests, long term reliability investigations and reinforcement possibilities of the boards and casings to ensure the required durability of the circuits. With the use of reinforcements, the application of trough hole mounted connectors should also be taken into account for enabling total compatibility with common assembling technologies.

\section{Acknowledgement}

The research was supported by the ProProgressio foundation. The help of Levente Dudás (BME HVT) is highly appreciated.

\section{References}

[1] Hogue, C. "Growing Piles of Toxic Trash." Chemical \& Engineering News. 88(9), p. 15. 2010.

[2] Illyefalvi-Vitéz, Z., Pinkola, J., Harsányi, G., Dominkovics, C., Illés, B., Tersztyánszky, L. "Present status of transition to Pb-free soldering." In: Proceedings of 28th IEEE-ISSE Conference, Vienna Neustadt, Austria, 19-20 May, 2005 . pp. 72-77. DOI: 10.1109/ISSE.2005.1491006

[3] Illyefalvi-Vitéz, Z., Krammer, O., Pinkola, J. "Testing the Impact of Pbfree Soldering on Reliability." In: 2006 1st Electronic Systemintegration Technology Conference, Dresden, Germany, Sep. 5-7, 2006, pp. 468473. DOI: 10.1109/ESTC.2006.280043

[4] Kaeb, H. "Bioplastics Bioplastics: Technology, Markets, Policies." In: 4th European Bioplastics Conference, Berlin, 10-11 November 2009.

[5] "Bioplastics - Frequently Asked Questions (FAQs)." 2008. [Online]. Available from: http://www.european-bioplastics.org/ [Accessed: 4th April 2011] 
[6] "Standard DIN EN 12432 - Proof of compostability of plastic products."

[7] Staat, A., Hohlfeld, T., Standau, T., Weimann, I., Bauer, R., Harre, K. "Substrates based on renewable resources for printed circuit boards." In: Proceedings of the 2014 37th International Spring Seminar on Electronics Technology, Dresden, May 7-11, 2014, pp. 50-53. DOI: $10.1109 /$ ISSE.2014.6887560

[8] Staat, A., Vogt, M., Harre, K., Bauer, R. "Effect of incorporation of different additives in sustainable polymers on selected electrical and mechanical properties." In: 2015 38th International Spring Seminar on Electronics Technology (ISSE). Eger, Hungary, May 6-10, 2015, pp. 2125. DOI: $10.1109 /$ ISSE.2015.7247954

[9] Staat, A., Köhler, A., Vogt, M., Bauer, R., Harre, K. "Effect of incorporation of additive combinations in polylactic acid on selected electrical properties." In: European Polymer Federation Congress, Germany, 2015.

[10] Ohki, Y., Hirai, N. "Electrical Conduction and Breakdown Properties of Several Biodegradable Polymers." IEEE Transactions on Dielectrics and Electrical Insulation. 14(6), pp. 1559-1566. DOI: 10.1109/TDEI.2007.4401240

[11] Hirai, N., Ishikawa, H., Ohki, Y. "Electrical conduction properties of several biodegradable polymers." In: Annual Report Conference on Electrical Insulation and Dielectric Phenomena. CEIDP, Vancouver, BC, Oct. 14-17, 2007. DOI: 10.1109/CEIDP.2007.4451542

[12] Mattana, G., Briand, G., Marette, A., Vásquez Quintero, A., de Rooij, N. F. "Polylactic acid as a biodegradable material for all-solution-processed organic electronic devices." Organic Electronics. 17, pp. 77-86. 2015. DOI: 10.1016/j.orgel.2014.11.010

[13] Vásquez Quintero, A., Frolet, N., Marki, D., Marette, A., Mattana, G., Briand, D., de Rooij, N. F. "Printing and encapsulation of electrical conductors on polylactic acid (PLA) for sensing applications." In: 2014 IEEE 27th International Conference on Micro Electro Mechanical Systems (MEMS). San Francisco, CA, Jan. 26-30, 2014, pp. 532-535. DOI: 10.1109/MEMSYS.2014.6765695

[14] Haroon, Ullah, S., Flint, J. A. "Electro-textile based wearable patch antenna on biodegradable polylactic acid (PLA) plastic substrate for 2.45 GHz, ISM band applications." In: 2014 International Conference on Emerging Technologies (ICET), Islamabad, Dec. 8-9, 2014, pp. 158-163. DOI: 10.1109/ICET.2014.7021036

[15] Hwang, S.-W., Song, J.-K., Huang, X., Cheng, H., Kang, S.-K., Kim, B. H., Kim, J.-H., Yu, S., Huang, Y., Rogers, J. A. "High-Performance Biodegradable/Transient Electronics on Biodegradable Polymers." Advanced Materials. 26(23), pp. 3905-3911. DOI: 10.1002/adma.201306050

[16] Géczy, A., Gál, L., Dudás, L., Horváth, G., Kovács, B., Nagy, D., Hajdu, I. "Experimental 13.56 MHz RFID cards on biodegradable substrates." In: 38th International Spring Seminar on Electronics Technology (ISSE). Eger, Hungary, May 6-10, 2015, pp. 52-56. DOI: 10.1109/ISSE.2015.7247961

[17] Schramm, R., Reinhardt, A., Franke, J. "Capability of Biopolymers in Electronics Manufacturing." In: 35th International Spring Seminar on Electronics Technology - Power Electronics (ISSE). Bad Aussee, Austria, May 9-13, 2012, pp. 345-349. 2012. DOI: 10.1109/ISSE.2012.6273157

[18] Baecker, M., Schusser, S., Leinhos, M., Poghossian, A., Schoening, M. J. "Sensor system for the monitoring of degradation processes of biodegradable biopolymers." In: Proceedings of Sensors and Measuring Systems 2014; 17. ITG/GMA Symposium, Nuremberg, Germany, June 3-4, 2014, pp. 1-4.

[19] Irimia-Vladu, M. "'Green" electronics: biodegradable and biocompatible materials and devices for sustainable future." Chemical Society Reviews. 43(2), pp. 588-610. 2014. DOI: 10.1039/c3cs60235d
[20] Medgyes, B., Hajdu, I., Berenyi, R., Gal, L., Ruszinko, M., Harsanyi, G. "Electrochemical migration of silver on conventional and biodegradable substrates in microelectronics." In: 37th International Spring Seminar on Electronics Technology (ISSE), Dresden, Germany, May 7-11, 2014, pp. 256-260. DOI: 10.1109/ISSE.2014.6887604

[21] Niedermann, P., Szebényi, G., Toldy, A. "Characterization of high glass transition temperature sugar-based epoxy resin composites with jute and carbon fibre reinforcement." Composites Science and Technology. 117, pp. 62-68. 2015. DOI: 10.1016/j.compscitech.2015.06.001

[22] Elkamel, A., Simon, L., Tsai, E., Vinayagamoorthy, V., Bagshaw, I., Al-Adwani, S., Mahdi, K. "Modeling the Mechanical Properties of Biopolymers for Automotive Applications." In: Proceedings of the 2015 International Conference on Industrial Engineering and Operations Management (IEOE). Dubai, United Arab Emirates (UAE), March 3-5, 2015. DOI: 10.1109/IEOM.2015.7093885

[23] Pal, R.-K., Farghaly, A.-A., Wang, C., Collinson, M. M., Kundu, S. C., Yadavalli, V. K. "Conducting polymer-silk biocomposites for flexible and biodegradable electrochemical sensors." Biosensors and Bioelectronics. 81, pp. 294-302. 2016. DOI: 10.1016/j.bios.2016.03.010

[24] Kanaparthi, S., Badhulika, S. "Solvent-free fabrication of a biodegradable all-carbon paper based field effect transistor for human motion detection through strain sensing." Green Chemistry. 18(12), pp. 3640-3646. 2016. DOI: 10.1039/c6gc00368k

[25] Luvisi, A., Panattoni, A., Materazzi, A. "RFID temperature sensors for monitoring soil solarization with biodegradable films." Computers and Electronics in Agriculture. 123(C), pp. 135-141. 2016.

DOI: 10.1016/j.compag.2016.02.023

[26] Rossiter, J., Winfield, J., Ieropoulos, I. "Here today, gone tomorrow: biodegradable soft robots." In: Electroactive Polymer Actuators and Devices (EAPAD), 2016. Proceedings of SPIE. Vol. 9798, 2016. DOI: $10.1117 / 12.2220611$

[27] Deng, J., Paraskevas, D., Tian, Y., Van Acker, K., Dewulf, W., Duflou, J. R. "Life cycle assessment of flax-fibre reinforced epoxidized linseed oil composite with a flame retardant for electronic applications." Journal of Cleaner Production. 133, pp. 427-438.

DOI: 10.1016/j.jclepro.2016.05.172

[28] Staat, A., Mende, R., Schumann, R., Harre, K., Bauer, R. "Investigation of wiring boards based on biopolymer substrates." In: Proceedings of 39th International Spring Seminar on Electronics Technology (ISSE) 2016, Pilzen, Czech Republic. Paper A17, 2016. (under publishing)

[29] Geczy, A., Lener, V., Hajdu, I., Illyefalvi-Vitez, Z. "Low temperature soldering on biopolymer (PLA) Printed Wiring Board substrate." In: Proceedings of the 2011 34th International Spring Seminar on Electronics Technology (ISSE), Tratanska Lomnica, Slovakia, May 11-15, 2011, pp. 57-62.DOI: 10.1109/ISSE.2011.6053550

[30] Geczy, A., Gal, L., Hajdu, I., Kovacs, B., Nagy, D., Ruszinko, M. "Optimizing solder joints on biodegradable PCBs with vapour phase soldering." In: Proceedings of the 2014 37th International Spring Seminar on Electronics Technology, Dresden, Germany, May 7-11, 2014, pp. 33-38. DOI: 10.1109/ISSE.2014.6887557

[31] Pietrikova, A., Durisin, J. "VPS and reliability of solder joint." In: Design and Technology of Electronics Packages, (SIITME) 2009 15th International Symposium for, Gyula, 2009, pp. 395-398. DOI: 10.1109/SIITME.2009.5407338

[32] Skwarek, A., Synkiewicz, B., Kulawik, J., Guzdek, P., Witek, K., Tarasiuk, J. "High temperature thermogenerators made on DBC substrate using vapour phase soldering." Soldering and Surface Mount Technology. 27(3), pp. 125-128. 2015. DOI: 10.1108/SSMT-04-2015-0017 
[33] Krammer, O. "Comparing the reliability and intermetallic layer of solder joints prepared with infrared and vapour phase soldering." Soldering and Surface Mount Technology. 26(4), pp. 214-222. 2014. DOI: 10.1108/SSMT-09-2013-0023

[34] Vajk, I., Harsányi, G., Poppe, A., Imre, S., Kiss, B., Jobbágy, A., Katona, G., Nagy, L., Magyar, G., Kiss, I. "BME VIK Annual Research Report on Electrical Engineering and Computer Science 2015." Periodica Polytechnica Electrical Engineering and Computer Science. 60(1), pp. 1-36. 2016. DOI: 10.3311/PPee.9124

[35] Niedermann, P., Szebényi, G., Toldy, A. "Novel high glass temperature sugar-based epoxy resins: Characterization and comparison to mineral oil-based aliphatic and aromatic resins." eXPRESS Polymer Letters. 9(2), pp. 85-94. 2015. DOI: 10.3144/expresspolymlett.2015.10

[36] ISO/IEC 14443-1:2008 Part 1, Identification cards. Contactless integrated circuit cards. Proximity cards. Part 1: Physical characteristics. 2008-06-15.

[37] Finkenzeller, K. "The Manufacture of Transponders and Contactless Smart Cards." In: RFID Handbook: Fundamentals and Applications in Contactless Smart Cards, Radio Frequency Identification and near-Field Communication, Third Edition, John Wiley \& Sons, Ltd, Chichester, UK, 2010. DOI: 10.1002/9780470665121.ch12

[38] Grover, F. W. "Inductance calculations: working formulas and tables." Dover Publications, Inc., Mineola, New York, 2009.
[39] keychain tag antenna coil [Online]. Available from: http://www.fasttech. com/products/1020/10002712/1201006 [Accessed: 25 th April 2014]

[40] Mohan, S. S., Hershenson, M. D., Boyd, S. P., Lee, T. H. "Simple Accurate Expressions for Planar Spiral Inductances." IEEE Journal of SolidStaate Circuits. 34(10), pp. 1419-1424. 1999. DOI: 10.1109/4.792620

[41] Andres Olivares - AndyMP3 Player Design. [Online]. Available from: http://andres.olivaresvergara.com/index.php?page=MP3+Player, 2013/04/17 [Accessed: 14 $4^{\text {th }}$ May 2015]

[42] Géczy A., Kovács, M., Hajdu, I. "Conductive layer deposition and peel tests on biodegradable printed circuit boards." In: 2012 IEEE 18th International Symposium for Design and Technology of Electronics Packages, SIITME 2012, Alba Iulia, Romania, Oct. 25-28, 2012, pp. 139-142. DOI: 10.1109/SIITME.2012.6384363

[43] Krammer, O., Molnar, L. M., Jakab, L., Szabo, A. "Modelling the effect of uneven PWB surface on stencil bending during stencil printing process." Microelectronics Reliability. 52(1), pp. 235-240. 2012. DOI: 10.1016/j.microrel.2011.08.012

[44] Krammer, O., Molnar, L. M., Jakab, L., Klein, C. "Stencil deformation during stencil printing." In: 2009 IEEE 15th International Symposium for Design and Technology of Electronics Packages, SIITME 2009, Gyula, Hungary, Sept. 17-20, 2009 pp. 179-184. DOI: 10.1109/SIITME.2009.5407378 